\title{
Carbazole electrochemistry: a short review
}

\author{
Krzysztof Karon $^{1} \cdot$ Mieczyslaw Lapkowski $^{1,2}$
}

Received: 16 February 2015 / Revised: 9 July 2015 / Accepted: 13 July 2015 / Published online: 4 August 2015

(C) The Author(s) 2015. This article is published with open access at Springerlink.com

\begin{abstract}
Carbazole and its derivatives have become important materials for optoelectronic applications in recent years. In this work, we have collated information on the oxidation of carbazole and its derivatives. Knowledge of their electrochemical properties affords insight into the mechanisms for their oxidation and reduction as well as possible subsequent reactions. This knowledge therefore provides the basis for evaluating the stabilities of these materials and for designing novel carbazole-derived materials with desired properties as well as new devices.
\end{abstract}

\section{Introduction}

The chemistry of carbazole has been studied for many years. However, carbazole and carbazole-derived materials, including polymers, have attracted considerable attention in recent years since they very useful materials in the field of optoelectronics. The literature contains a great deal of information on the synthesis of numerous carbazole-based compounds, investigations of their optical properties, and their use in optoelectronic devices. Regardless of the form of the carbazole compound of interest, knowledge of its electronic

We dedicate this article to Prof. M. A. Vorotyntsev in celebration of his 70th birthday.

\section{Krzysztof Karon}

krzysztof.karon@polsl.pl

1 Faculty of Chemistry, Silesian University of Technology, Strzody 9, 44-100 Gliwice, Poland

2 Centre of Polymer and Carbon Materials, Polish Academy of Science, Curie Sklodowska 34, 41-800 Zabrze, Poland properties and the mechanisms for its oxidation/reduction and subsequent reactions is crucial to its practical application. A detailed knowledge of the properties of simple carbazoles and their polymers and a deep understanding of the relationship between the properties of such monomers and polymers are of great importance, and represent the foundation for designing useful carbazole-based polymeric materials with desired properties.

The most recent review of carbazole electrochemistry was actually published a rather long time ago; indeed, no such review appears to have been provided since the work of Ambrose and Nelson [1, 2]. Therefore, in this paper we have collated information on the oxidation of carbazole and its derivatives from various sources.

\section{Chemical oxidation of carbazoles}

Carbazole is readily oxidized but may form various products depending on the reaction conditions. The first studies on the oxidation of carbazole involved chemical oxidation with various media.

The first significant work on the oxidation of carbazole was published by Branch and Tucker [3-5]. Branch reported that when silver oxide was used as an oxidant, two products were obtained, one of them being 9,9'-bicarbazyl [3, 4]. Trucker used potassium permanganate in acetone as an oxidant and received three products: A, B, and C. Product A was 9,9'bicarbazyl [5]. Further works proved that products $\mathrm{B}$ and $\mathrm{C}$ were tricarbazyl (Fig. 1b) and a mixture of oligomers (Fig. 1c, d, e, and f) $[7,8]$.

When the oxidation is carried out in an acidic medium, for example with dichromate in an acetic acid/sulfuric acid solution, only $3,3^{\prime}$-bicarbazole is obtained [9]. This proves that the process of combining the carbazole moieties at the $\mathrm{N}-\mathrm{N}^{\prime}$ bond, which requires the loss of the proton attached 
Fig. 1 Products that form upon the oxidation of carbazole with potassium permanganate in acetone [6]
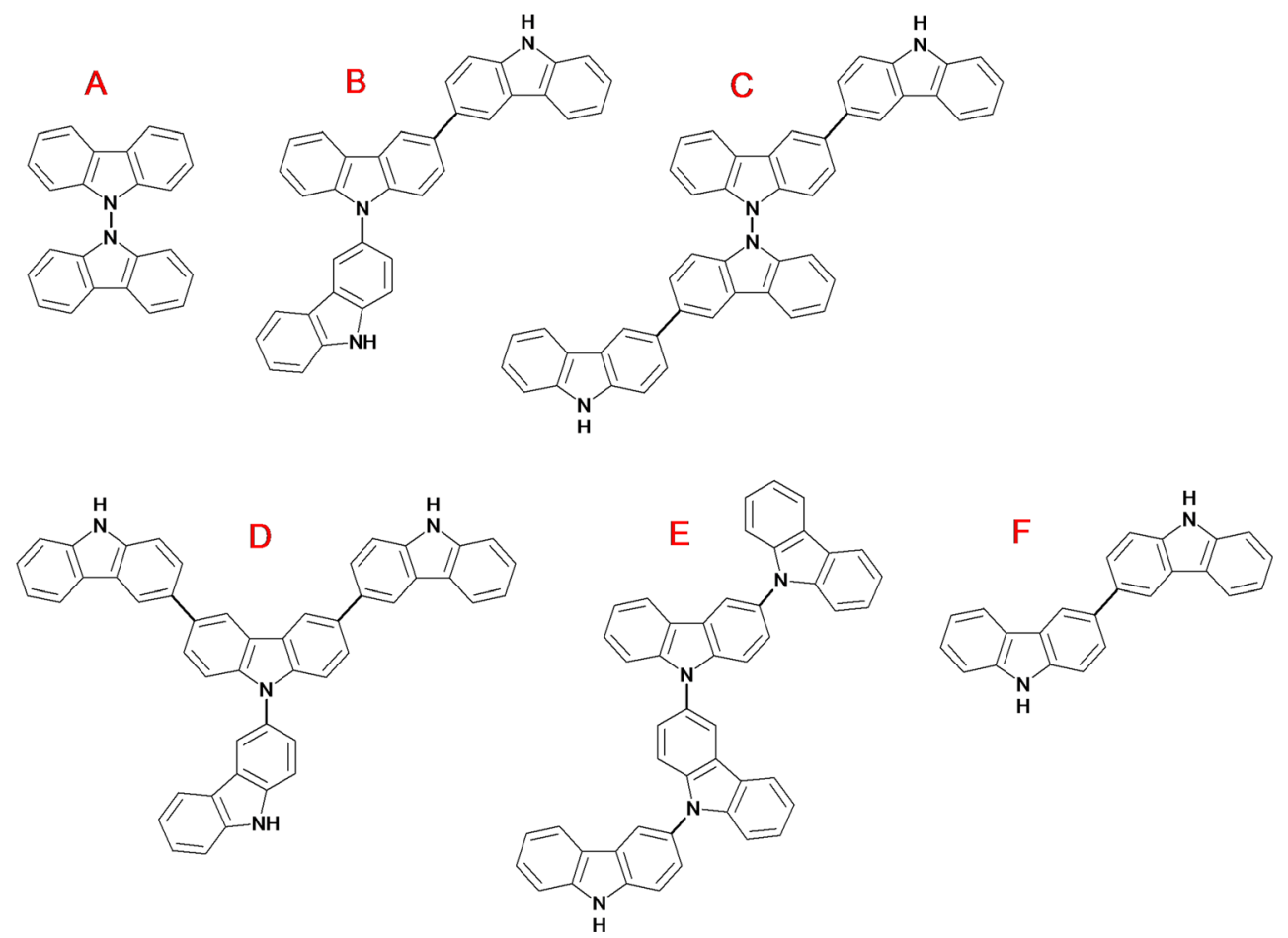

to the nitrogen atom at some point, is prevented in acidic media. When the nitrogen atom is blocked by a substituent (e.g., a methyl group), the oxidation leads mainly to dimers. Further reactions are suppressed as a result of charge delocalization between the two coupled nitrogen atoms in dicarbazole.

On the other hand, when this coupling is hindered, higher oligomers or even a polymer can be obtained. It has been shown that polymerization occurs during the oxidation of 1,4,5,8,9-pentamethylocarbazole with iron(III) chloride. Steric hindrance of adjacent monomer units causes chain twisting (torsion angle is $60^{\circ}$ ), so $\pi$-coupling between two successive units becomes difficult. This allows the polymerization reaction to proceed at positions 3 and 6 , as shown in Fig. 2 [9].
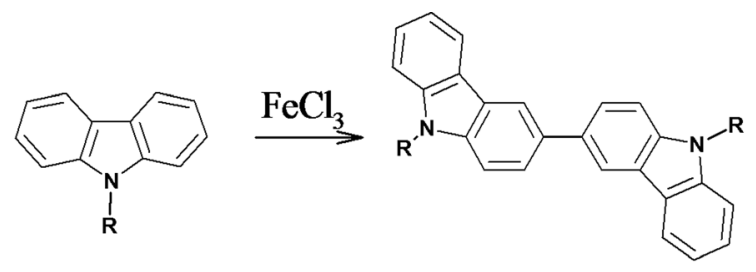

n<smiles>Cc1ccc(C)c2c1c1c(C)ccc(C)c1n2C</smiles>
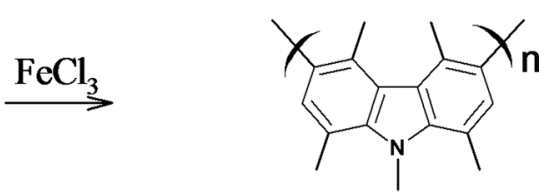

Fig. 2 Oxidation of carbazole and 1,4,5,8,9-pentamethylocarbazole with iron(III) chloride

\section{Electrochemical oxidation of carbazoles}

Electrochemical oxidation of carbazole proceeds in a similar way to chemical oxidation but seems to be more selective. The first and most significant work on the electrochemical oxidation of carbazole was published by Ambrose and Nelson [1], who explained the process in detail and confirmed the presence of various reaction products by comparing the $\mathrm{CVs}$ of the relevant compounds synthesized chemically.

Carbazole is oxidized at a potential of approximately $1.2 \mathrm{~V}$ vs. SCE, forming the cation radical in a oneelectron process. As the cation radical is very unstable, it tends to couple with either another cation radical or with a parent molecule, forming the more stable dicarbazyl. The coupling is accompanied by the loss of two protons, one per carbazole unit, but it is still not known when the proton loss occurs, i.e., before or after coupling. Lost protons are further reduced in the cathodic cycle [1]. As a result of coupling, two products are obtained (Fig. 3): 3, 3'bicarbazyl, the main product, and 9,9'-bicarbazyl, the minor product. QM calculations of the electron density in carbazole suggest that coupling could occur at positions 1, 3, 6, 8 , and 9. This seems to be roughly consistent with experimental data. However, small amounts of products that are substituted at position 1 or 8 are not seen, mainly due to steric hindrance [1].

3-3'-Dicarbazyl is more readily oxidized than carbazole. It undergoes two successive, reversible, one-electron oxidation steps to the cation radical and the quinoid-like dication, respectively (Fig. 3). These processes occur at approximately 
Fig. 3 Mechanisms for the electrochemical oxidation of carbazole [1]

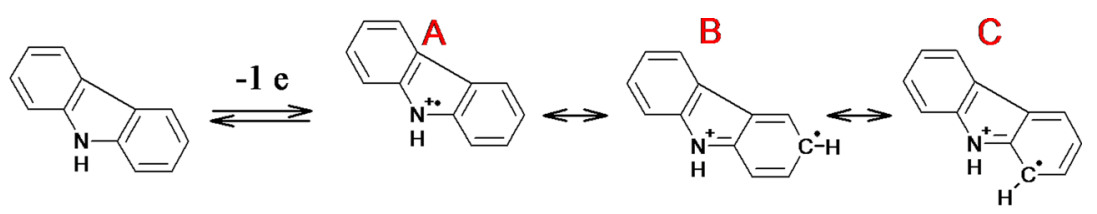

$2 \mathrm{~B}$

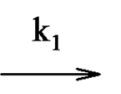<smiles>O=Cc1ccc2[nH]c3ccccc3c2c1</smiles>

$+2 \mathrm{H}^{+}$

$2 \mathrm{~A}$

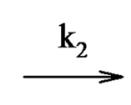

E

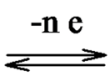

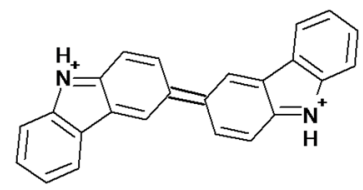

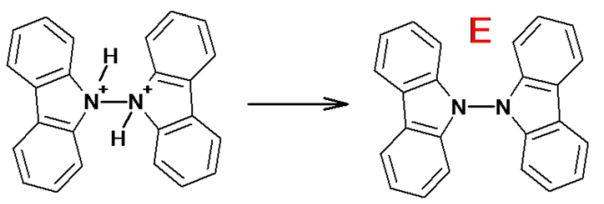

$+2 \mathrm{H}^{+}$
0.8 and $1.1 \mathrm{~V}$ vs SCE. In repetitive scans, these peaks are also seen on the $\mathrm{CV}$ for carbazole. It is much more difficult to oxidize the second product, 9,9'-bicarbazyl; oxidation of this product reveals two peaks at approximately 1.45 and $1.8 \mathrm{~V}$ vs. SCE (which are again visible on the CV for the oxidation of carbazole when scanning to higher anodic potentials). This oxidation is irreversible, but unfortunately the products are still unknown.

The oxidation of carbazole is rather complex, and has the characteristics of an ECE process in which one electron is involved per parent molecule (i.e., one electron for the oxidation of each carbazole molecule and two per dicarbazyl). In fact, due to the possible formation of two products (one of which is more easily oxidized), chronoamperometric investigation usually indicates that 2.5-2.8 electrons are involved in the whole process of carbazole oxidation [1].

The mechanism described here appears many times in the literature in descriptions of carbazole electropolymerization or the process of polymer crosslinking via dicarbazole bridging [10-16].

It is worth noting that carbazole oxidation is also $\mathrm{pH}$ sensitive. It has been proven that the formation of 9,9'-bicarbazyl requires a low proton concentration. In fact, the release of protons during the oxidation of carbazole is the reason for the low concentration of 9,9'-bicarbazyl. Carrying out the reaction at a high proton concentration suppresses the formation of 9-9'-dicarbazyl, while the addition of proton-binding agents (e.g., pyridine) enhances it. This phenomenon can be used to measure the $\mathrm{pH}[1,17]$.

\section{$\mathrm{N}$-substituted carbazoles}

$N$-substituted carbazoles generally behave in a similar way to pure carbazole, although there are some exceptions [2, 15-19]. Ambrose reports that the oxidation potential depends slightly on the characteristics of the substituent, as shown in Table 1 [2]. Electrochemical oxidation occurs in exactly the same way as for carbazole but leads only to 3,3'-bicarbazyl. This obviously results from the fact that the 9-position is already occupied. A detailed study of the oxidation of $N$-alkyl carbazoles suggests that oxidation and dimerization occur quantitatively; dimer oxidation, on the other hand, involves exactly two electrons per carbazole unit.

For $N$-aryl-carbazoles, oxidation should also lead to reactive radicals that are delocalized on the $N$-aryl and then to other products, but this is not observed. The only product that is formed during the oxidation of $N$-phenyl carbazole is 9,9'-diphenyl-3,3'-bicarbazyl. This can be explained by steric hindrance, as this molecule is twisted (not planar), so the $\mathrm{N}$-phenyl and carbazole orbitals are not sufficiently conjugated. This has been confirmed by numerous results from QM calculations [2]. The oxidation potential of 9phenylcarbazole is not very sensitive to substituents at the para position on the 9-phenyl group, but is of course very sensitive to any substituent at the 3- or 6-position on the carbazole [31].

Among $N$-substituted carbazoles, the most interesting is $N$ vinyl carbazole (NVC). According to the literature [20, 32], the oxidation of this molecule occurs in a similar manner to 
Table 1 Electrochemical properties of various carbazole derivatives

$\begin{array}{llll}E_{\mathrm{p}} / 2, \text { in } \mathrm{V} & \begin{array}{l}n \text { value (total), } \\ \text { in } e / \mathrm{mol}\end{array} & \text { Products and comments } & \text { Reference }\end{array}$

\begin{tabular}{|c|c|c|c|c|}
\hline \multirow[b]{2}{*}{$\mathrm{H}$} & \multicolumn{4}{|c|}{$N$-substituted carbazoles } \\
\hline & 1.16 & $2.5-2.8$ & Various products, mainly 3-3'- and 9-9'-bicarbazoles & {$[1]$} \\
\hline $\mathrm{CH}_{3}$ & 1.10 & 1.96 & 3,3'-Bicarbazyl & {$[1]$} \\
\hline $\mathrm{C}_{2} \mathrm{H}_{5}$ & 1.12 & 2.01 & 3,3'-Bicarbazyl & {$[1]$} \\
\hline $\mathrm{C}\left(\mathrm{CH}_{3}\right)_{2}$ & 1.14 & 2.01 & 3,3'-Bicarbazyl & {$[1]$} \\
\hline $\mathrm{C}_{6} \mathrm{H}_{5}$ & 1.21 & 2.08 & 3,3'-Bicarbazyl & {$[1]$} \\
\hline $\mathrm{C}_{6} \mathrm{H}_{5}$ & $1.38 \mathrm{vs} \mathrm{Ag} / \mathrm{AgCl}$ & - & Irreversible oxidation, preferably to $3,3^{\prime}$-bicarbazyl & {$[19]$} \\
\hline $\mathrm{C}_{6} \mathrm{H}_{5}-\mathrm{CH}_{3}$ & $1.38 \mathrm{vs} \mathrm{Ag} / \mathrm{AgCl}$ & - & Irreversible oxidation preferably to $3,3^{\prime}$-bicarbazyl & {$[19]$} \\
\hline $\mathrm{C}_{6} \mathrm{H}_{5}-\mathrm{OCH}_{3}$ & $1.33 \mathrm{vs} \mathrm{Ag} / \mathrm{AgCl}$ & - & Irreversible oxidation, preferably to $3,3^{\prime}$-bicarbazyl & {$[19]$} \\
\hline $\mathrm{C}_{6} \mathrm{H}_{5}-\mathrm{NO}_{2}$ & $1.48 \mathrm{vs} \mathrm{Ag} / \mathrm{AgCl}$ & - & Irreversible oxidation, preferably to $3,3^{\prime}$-bicarbazyl & {$[19]$} \\
\hline $\mathrm{C}_{6} \mathrm{H}_{5}-\mathrm{NH}_{2}$ & $0.93,1.31 \mathrm{vs} \mathrm{Ag} / \mathrm{AgCl}$ & - & Irreversible oxidation, preferably to $3,3^{\prime}$-bicarbazyl & {$[19]$} \\
\hline $\mathrm{CHCH}_{2}$ - vinyl & $1.2 \mathrm{~V}$ vs. SCE & - & Two forms of poly- $N$-vinyl carbazole with different properties & {$[20,32]$} \\
\hline $\begin{array}{r}\text { BNCVB (1,4-bis[( } E) \\
\text { 2-(9H-carbazol-9- } \\
\text { yl)vinyl]benzene) }\end{array}$ & $\begin{array}{c}0.91,1.06 \text { and } 1.29 \\
\text { V vs } \mathrm{Ag} / \mathrm{AgCl}\end{array}$ & - & Polymer with mainly $3,3^{\prime}$-coupling & {$[21]$} \\
\hline \multirow[t]{2}{*}{ NO } & 1.76 & - & 3,3'-Bicarbazyl & {$[1]$} \\
\hline & \multicolumn{4}{|c|}{ 3-Substituted carbazoles } \\
\hline $\mathrm{CH}_{3}$ & 1.12 & 2.6 & $6-6^{\prime}$ - and $N-N^{\prime}$-bicarbazyls formed in poor yield & {$[2]$} \\
\hline $\mathrm{F}$ & 1.23 & 3.4 & $6-6^{\prime}$ - and $N-N^{\prime}$-bicarbazyls formed in poor yield & {$[2]$} \\
\hline $\mathrm{Cl}$ & 1.27 & 3.4 & $6-6^{\prime}$ - and $N-N^{\prime}$-bicarbazyls formed in poor yield & {$[2]$} \\
\hline $\mathrm{Br}$ & 1.26 & 3.2 & $6-6^{\prime}$ - and $N-N^{\prime}$-bicarbazyls formed in poor yield & {$[2]$} \\
\hline I & 1.25 & 3.0 & $6-6^{\prime}$ - and $N-N^{\prime}$-bicarbazyls formed in poor yield & {$[2]$} \\
\hline $\mathrm{CN}$ & 1.43 & 4.0 & $6-6^{\prime}$ - and $N-N^{\prime}$-bicarbazyls formed in poor yield & {$[2]$} \\
\hline $\mathrm{NO}_{2}$ & 1.51 & 4.0 & Unknown product & {$[2]$} \\
\hline $\mathrm{NH}_{2}$ & 0.47 & 0.99 & Unstable cation radical; coupled products appear (as shown in Fig 6) & {$[2]$} \\
\hline \multirow[t]{2}{*}{$\mathrm{N}\left(\mathrm{CH}_{3}\right)_{2}$} & 0.38 & 0.98 & $\begin{array}{l}\text { Reversible oxidation to a stable cation radical; second reversible } \\
\text { oxidation at } 1.0 \mathrm{~V} \text { to a stable dication (as shown in Fig 6) }\end{array}$ & {$[2]$} \\
\hline & \multicolumn{4}{|c|}{ 3-Substituted- $N$-ethyl carbazoles } \\
\hline $\mathrm{CH}_{3}$ & 1.09 & 2.08 & $6,6^{\prime}$-Bicarbazyl (40 \%) & {$[2]$} \\
\hline $\mathrm{F}$ & 1.20 & 2.03 & 6,6'-Bicarbazyl (100 \%) & [2] \\
\hline $\mathrm{Cl}$ & 1.28 & 1.93 & 6,6'-Bicarbazyl $(60 \%)$ & {$[2]$} \\
\hline $\mathrm{Br}$ & 1.25 & 2.13 & 6,6'-Bicarbazyl (50 \%) & {$[2]$} \\
\hline I & 1.24 & 2.20 & 6,6'-Bicarbazyl (60\%) & {$[2]$} \\
\hline $\mathrm{CHO}$ & 1.34 & 2.09 & 6,6'-Bicarbazyl (very weakly soluble product) & {$[2]$} \\
\hline $\mathrm{CN}$ & 1.44 & 2.24 & 6,6'-Bicarbazyl $(60 \%)$ & {$[2]$} \\
\hline $\mathrm{NO}_{2}$ & 1.46 & 2.26 & $6,6^{\prime}$-Bicarbazyl (50 \%) & {$[2]$} \\
\hline $\mathrm{NH}_{2}$ & 0.48 & 0.75 & Unstable cation radical; coupled products (as shown in Fig 6) & {$[2]$} \\
\hline \multirow[t]{2}{*}{$\mathrm{N}\left(\mathrm{CH}_{3}\right)_{2}$} & 0.36 & 0.98 & $\begin{array}{l}\text { Stable cation radical; second oxidation at } 0.98 \mathrm{~V} \text { to a stable } \\
\text { dication (as shown in Fig 6) }\end{array}$ & {$[2]$} \\
\hline & \multicolumn{4}{|c|}{ 3,6-Disubstituted carbazoles } \\
\hline $\mathrm{OCH}_{3}$ & 0.78 & 1.76 & Stable cation radical & {$[2]$} \\
\hline$t-\mathrm{Bu}$ & 1.07 & $2.91,1.87$ & 9,9'-Bicarbazyl (90-100\%) & {$[2]$} \\
\hline $\mathrm{Cl}$ & 1.38 & 3.6 & 3,3'- and 9,9'-Bicarbazyls & {$[2]$} \\
\hline $\mathrm{Br}$ & 1.37 & $2.87,1.93$ & 9,9'-Bicarbazyl (90-100\%) & {$[2]$} \\
\hline I & 1.34 & 1.88 & 3,3'- and 9,9'-Bicarbazyls & {$[2]$} \\
\hline $\mathrm{CN}$ & 1.71 & 3.04 & Unknown product & {$[2]$} \\
\hline \multirow[t]{2}{*}{$\mathrm{NO}_{2}$} & 1.84 & 2.68 & Unknown product & {$[2]$} \\
\hline & \multicolumn{4}{|c|}{ 3,6-Disubstituted- $N$-ethyl carbazoles } \\
\hline $\mathrm{OCH}_{3}$ & 0.8 & 1.01 & Stable cation radical; unstable dication & {$[2]$} \\
\hline $\mathrm{CH}_{3}$ & 1.04 & 2.2 & $\begin{array}{l}\text { Moderately stable cation radical; decomposition accompanied } \\
\text { by coupling through methyl group }\end{array}$ & {$[2]$} \\
\hline $\mathrm{C}_{2} \mathrm{H}_{5}$ & 1.06 & 3.1 & & {$[2]$} \\
\hline
\end{tabular}


Table 1 (continued)

$\begin{array}{llll}E_{\mathrm{p}} / 2, \text { in } \mathrm{V} & \begin{array}{l}n \text { value (total), } \\ \text { in } e / \mathrm{mol}\end{array} & \text { Products and comments } & \text { Reference }\end{array}$

\begin{tabular}{|c|c|c|c|c|}
\hline & & & $\begin{array}{l}\text { Unstable cation radical; decomposition accompanied by } \\
\text { coupling through methyl group }\end{array}$ & \\
\hline$t$-Bu & 1.07 & 1.07 & Stable cation radical & {$[2]$} \\
\hline $\mathrm{Cl}$ & 1.48 & 1.30 & Moderately stable cation radical & {$[2]$} \\
\hline $\mathrm{Br}$ & 1.40 & 1.20 & Moderately stable cation radical & {$[2]$} \\
\hline I & 1.34 & 2 & Unstable cation radical; elimination of iodine to form 3,3'-bicarbazyl & {$[2]$} \\
\hline $\mathrm{CN}$ & 1.74 & 3.4 & Moderately stable cation radical & {$[2]$} \\
\hline $\mathrm{NO}_{2}$ & 1.81 & 3.8 & Moderately stable cation radical & {$[2]$} \\
\hline $\mathrm{NH}_{2}$ & 0.32 & 1.09 & Unstable cation radical & {$[2]$} \\
\hline $\mathrm{N}\left(\mathrm{CH}_{3}\right)_{2}$ & 0.22 & 1.03 & $\begin{array}{l}\text { Stable cation radical; second oxidation at } 0.60 \mathrm{~V} \text { to a stable } \\
\text { dication; unstable trication formed at } 1.41 \mathrm{~V}\end{array}$ & {$[2]$} \\
\hline Uncoupled aromatics & Approx. 1.15 & - & $\begin{array}{l}\text { Usually multistep oxidation; carbazole moiety is usually } \\
\text { oxidized to a stable cation radical at a potential similar to } \\
\text { that seen for the parent carbazole. }\end{array}$ & {$[23-27]$} \\
\hline Coupled aromatics & $\begin{array}{l}\text { Various potentials } \\
\text { for oxidation }\end{array}$ & - & $\begin{array}{l}\text { Usually multistep oxidation; first step is usually oxidation } \\
\text { to stable cations or dications }\end{array}$ & {$[28,29]$} \\
\hline $\begin{array}{l}\text { BCCVFluo (2,7-bis(9-ethyl- } \\
\text { 3-carbazo-vinylene)-9,9- } \\
\text { dihexyl-fluorene) }\end{array}$ & $0.85,1.1 \mathrm{~V}$ vs $\mathrm{Ag} / \mathrm{AgCl}$ & - & $\begin{array}{l}\text { Quite stable cation radical—coupling occurs, but very } \\
\text { slowly; polymerization occurs in second step of oxidation }\end{array}$ & - \\
\hline $\begin{array}{l}\text { BCCVAnth }(9,10 \text {-bis } \\
\quad \text { (9-ethyl-3-carbazo- } \\
\text { vinylene)-anthracene) }\end{array}$ & $\begin{array}{c}0.65,1.69 \text { and } 1.82 \\
\text { V vs } \mathrm{Ag} / \mathrm{AgCl}\end{array}$ & - & $\begin{array}{l}\text { Dication formed initially; further oxidation accompanied } \\
\text { by vinylene groups }\end{array}$ & - \\
\hline TC36 & $1.08,1.30 \mathrm{vs} \mathrm{Ag} / \mathrm{AgCl}$ & $\begin{array}{l}\text { Approx. } 1.4 \text { and } 3.1 \\
\text { (total in first and } \\
\text { second steps) }\end{array}$ & $\begin{array}{l}\text { Oxidation to a stable radical cation and dication; low tendency } \\
\text { for coupling }\left(3^{\prime}, 3^{\prime \prime} \text { coupling preferred) }\right.\end{array}$ & {$[27]$} \\
\hline $\mathrm{TC} 27$ & $1.15,1.37 \mathrm{~V}$ vs $\mathrm{Ag} / \mathrm{AgCl}$ & Approx. 1.2 (in first step) & $\begin{array}{l}\text { Firstly a stable radical cation and dication; further oxidation } \\
\text { accompanied by a high tendency for coupling } \\
\left(3^{\prime}, 3^{\prime \prime} \text { coupling preferred }\right)\end{array}$ & {$[27]$} \\
\hline $\begin{array}{l}\text { TNCPA }\left(4,4^{\prime}, 4^{\prime \prime} \text {-tris }(9-\right. \\
\text { carbazolyl }) \text { triphenylamine })\end{array}$ & $\begin{array}{l}0.94,1.14,1.40 \\
\text { V vs Ag/AgCl }\end{array}$ & $\begin{array}{l}\text { Approx. } 1.2 \text { and } 2.5 \\
\text { (total in first and } \\
\text { second steps) }\end{array}$ & $\begin{array}{l}\text { Firstly a stable radical cation and dication; further } \\
\text { oxidation accompanied by a high tendency for coupling }\end{array}$ & {$[30]$} \\
\hline
\end{tabular}

carbazole but is accompanied by further chemical reactions. Initial oxidation to the corresponding cation radical occurs at a potential of approximately $1.2 \mathrm{~V}$ vs. SCE, and is followed by fast dimerization at position 3 on the carbazole unit (Fig. 4). The protons released during dimerization trigger further vinyl group polymerization.

Two products can be obtained, as the protons attack either the vinyl group of the monomer in solution or the vinyl group of the growing polymer.

$\mathrm{H}^{+}$attack on the vinyl group of the growing electronconducting polymer causes crosslinking (Fig. 4, structure $\mathrm{G})$. Activation of the vinyl group of the monomer in solution leads to a white, comb-like, photoconducting polymer (Fig. 4, structure J).

The poly(3,6-N-vinylcarbazole) that forms on the anode surface exhibits different degrees of crosslinking depending on the synthetic conditions applied.

Reyna-Gonzalez et al. [20,32] demonstrated that modifying the acidity of the electrolyte leads to the formation of polymer films with various properties (in terms of morphology, chemical structure, thermal, optical properties, and electrical conductivity).
In some cases, the vinylene substituent at the carbazole nitrogen may significantly influence the conjugation length of the whole molecule and hence its oxidation. In a previous study [21], we showed that a molecule named BNCVB which consists of two carbazole units $N$-linked to an aromatic 1,4divinylbenzene bridge can be oxidized at a significantly lower potential than carbazole (Fig. 5).

The first step in the oxidation of BNCVB in solution occurs at a potential of $0.91 \mathrm{~V}$, and two additional peaks are observed at 1.06 and $1.29 \mathrm{~V}$. While the first two peaks, which have comparable currents, can be assigned to two monoelectronic BNCVB oxidation steps, the third peak (at $1.29 \mathrm{~V}$ ) appears to be due to the second oxidation step of the polymer deposited on the electrode. It should be noted that the polymerization of BNCVB is initiated immediately after the first monomer oxidation step, at around $0.95 \mathrm{~V}$. The decrease in the oxidation potential with respect to that of a carbazole or bicarbazole molecule with an aliphatic bridge $[22,33]$ unequivocally confirms the existence of much more extensive conjugation in the BNCVB molecule than in carbazole or an $N$-alkyl bicarbazole.

During oxidation, oligomerization occurs in a manner similar to carbazole, as proven by analyzing infrared spectra [21]. 
Fig. 4 Mechanisms for the electrochemical oxidation of $\mathrm{N}$ vinyl carbazole (NVC) [20, 32]

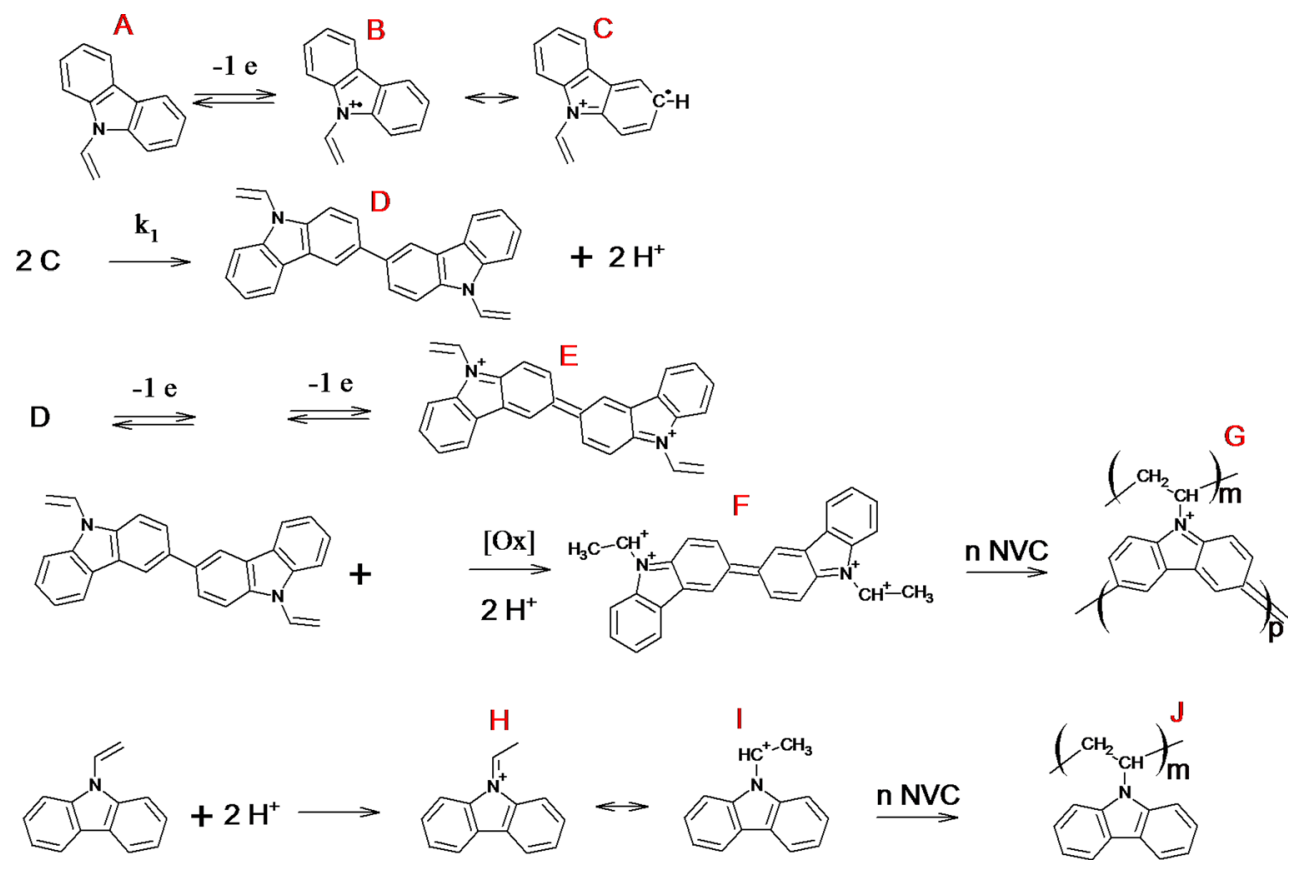

\section{3-Substituted carbazoles}

The electrochemistry of 3-substituted carbazoles is generally similar to that of pure carbazole, with some exceptions. Generally, oxidation leads to $6,6^{\prime}$ - and $N, N^{\prime}$-bicarbazyls that are formed in rather poor yield. The former product is usually favored and only a small amount of the 6-6' product is obtained, but the latter is produced in excess in the presence of a deprotonating species (see Fig. 6) [2]. It is obvious that the oxidation of 3-substituted- $N$-alkyl carbazoles will only give the 6,6'-dicarbazyl.

Ambrose reported that when 3-halogen-substituted carbazoles are oxidized, the only product is the 6-6'-bicarbazyl, regardless of the solution $\mathrm{pH}[2]$.

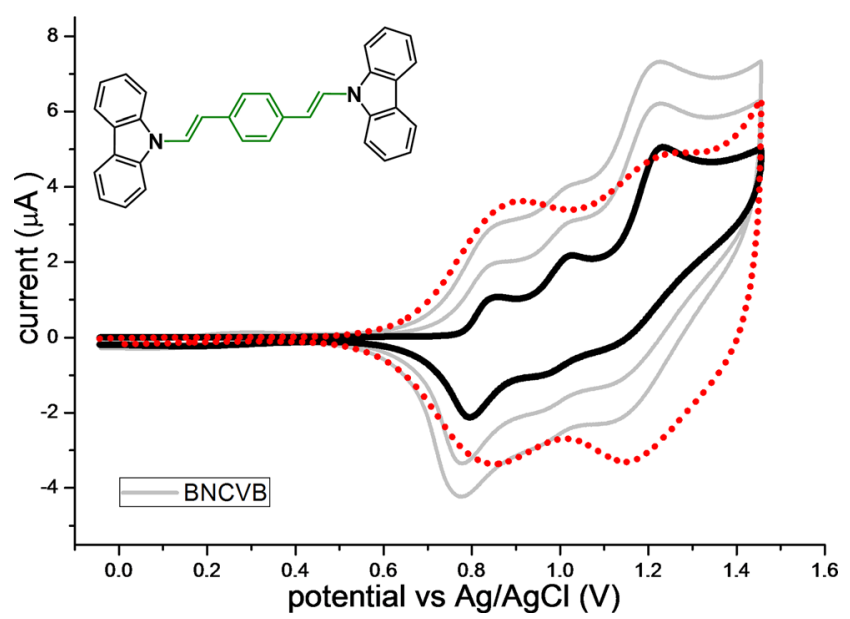

Fig. $5 \mathrm{CV}$ for the oxidation of BNCVB. The black line represents the first cycle while the gray lines depict subsequent scans. The dotted red line shows the $\mathrm{CV}$ for the polymer in monomer-free solution
Oxidation of 3-amino carbazole proceeds completely differently. In this case, oxidation occurs as an irreversible one-step and one-electron process at a significantly lower potential than that for the parent carbazole (i.e., at approximately $0.4 \mathrm{~V}$ ). This substantial reduction in oxidation potential results from the different electron density profile for 3-amino carbazole, due to the presence of the additional electron-rich amino group.

After oxidation to a cation radical, intermolecular coupling occurs, in which the $\mathrm{NH}_{2}$ group is probably involved. The structure of the coupled product has not been proven, but, according to charge density calculations, there are two mostprobable structures. They are the result of amine N-N or Nring coupling, as presented in Fig. 6; 6-6' coupling is unlikely in this case due to low electron density at the 6-position.

Oxidation of the 3-dimethylamino derivative proceeds in a different way. The oxidation takes place in two reversible oneelectron steps. The first redox process leads to a stable cation radical whose existence was confirmed by ESR spectroscopy [2]. In the second step, a dication with a quinonediimine-like pattern is created (see Fig. 6). According to the authors, no bicarbazyl was found: neither 6-6' nor 9-9' coupled [2].

If the aromatic group is attached at the 3-position, the mechanism of oxidation could be more complex.

The oxidation potential may depend on the type of substituent present and the way it is attached to the carbazole moiety. In the case of a lack of or only low steric hindrance, it is highly possible that the whole molecule is well conjugated and undergoes multiple-step oxidation to various subproducts. In that scenario, intramolecular coupling quite often occurs, leading to the formation of a stable dication and limiting further chemical reactions. On the other hand, steric hindrance may disturb or even block such intramolecular coupling, allowing 


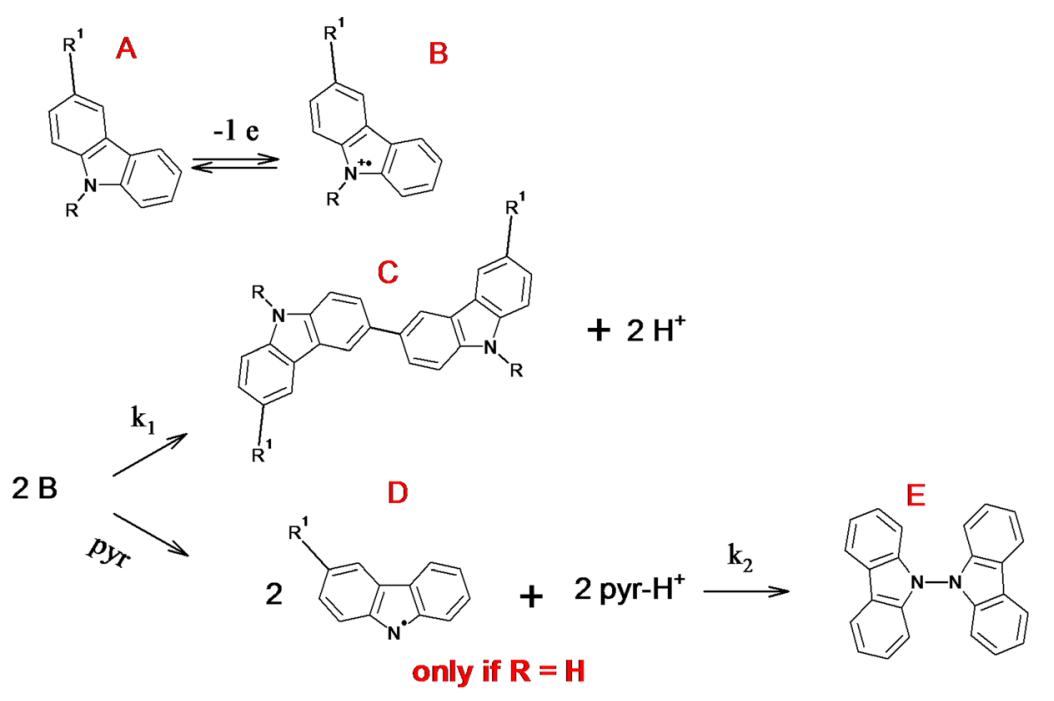

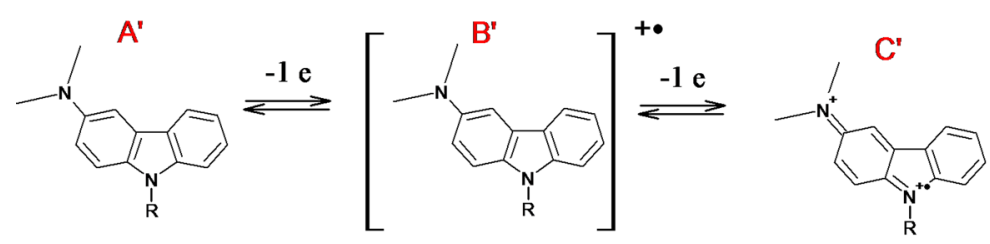
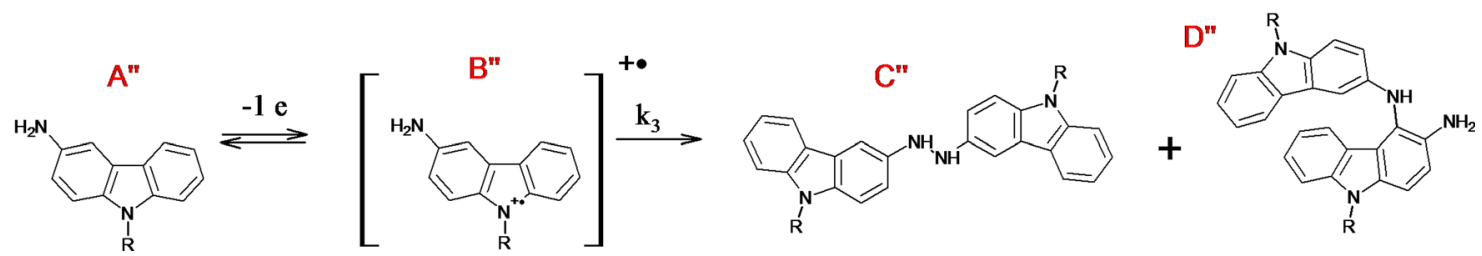

Fig. 6 Mechanisms for the oxidation of 3-substituted carbazole (top) and 3-dimethylamino derivatives (middle). Bottom: the two most likely products of 3-amino carbazole oxidation [11]

intermolecular coupling. Depending on the oxidation potential of the aromatic group and its tendency to couple, various copolymers - alternating or random - can form [28, 34].

When the 6-position on the carbazole is not substituted, coupling can occur at this site. A suitable substituent may, however, affect the density of electrons in the carbazole and prevent coupling.

When only minor steric hindrance is present, electronic effects become crucial. In this case, the extended $\pi$-electron system usually enhances radical stabilization through extended delocalization. Figure 7 presents voltammograms for a series of bis(9-ethyl-3-carbazo-vinylene) arenes that illustrate this phenomenon.

CVs registered during the oxidation of BCCVFluo in solution show two redox systems with maxima at around 0.8 and $1.4 \mathrm{~V}$. The first oxidation step is a typical semi-reversible process with a peak separation of $0.068 \mathrm{~V}$. Nevertheless, when scanning is repeated many (hundreds of) times, or when a slightly higher potential is applied, 6,6' coupled products form on the electrode. On the other hand, the monomer BCCVAnth behaves in different way. The voltammetric first oxidation peak, which is fully reversible, occurs at $0.65 \mathrm{~V}$; two more peaks then form at around 1.69 and $1.82 \mathrm{~V}$. In the first step, oxidation probably leads to a very stable dication, and the former is probably associated with vinylene bond oxidation.

\section{3,6-Disubstituted carbazoles}

The oxidation of most of the previously discussed simple carbazole derivatives, except for amino derivatives, leads to coupling, presumably at the 3- or 6-position. When the 3- and 6positions are already taken by another substituent, this coupling cannot occur, and the only likely coupling sites are the 1-, 8-, and 9-positions, yielding $1-1,1-\mathrm{N}$, and $\mathrm{N}-\mathrm{N}$ coupled products (Fig. 8). According to Ambrose [2], in the case of 3,6-dialkyl carbazoles, the main product is the 1-1'-bicarbazyl, while the 99 '-bicarbazyl is mainly obtained in the presence of a strong organic base. Other substituents can, however, lead to different behavior depending on the electron density at the active site, 


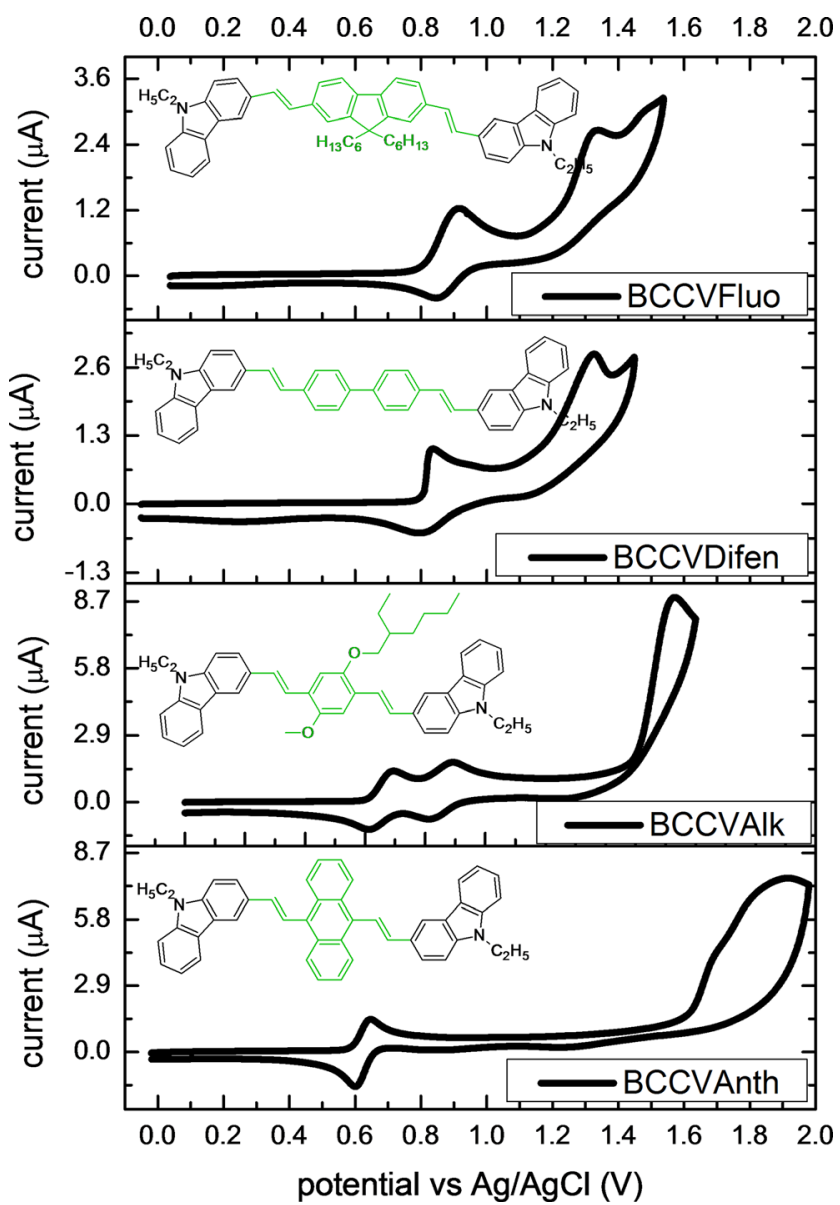

Fig. $7 \mathrm{CVs}$ for the oxidation of a series of bis(9-ethyl-3-carbazovinylene) arenes

and the process can also be affected by adsorption phenomena. A methoxy group, for instance, causes a decrease in electron density at the active site, resulting in a stable radical cation, while some elimination processes can occur with halogen derivatives, with coupling permitted at position 3 or 6 [2].

It is obvious that alkylating the nitrogen atom in 3,6-disubstituted carbazoles makes coupling at the 9-position impossible. However, in this case, coupling at the 1- or 8position cannot occur either, due to steric hindrance; oxidation then usually leads to a stable radical cation in a reversible one-electron process. In some cases, further oxidation or follow-up reactions can also occur, accompanied by the elimination of certain species such as a proton or a halogen atom, leading to further coupling [2]. Analogous results were obtained by Chinese researchers who investigated a series of 9-phenylcarbazoles and 3,6-substituted-9phenylcarbazoles [29]. For the 3,6-substituted-9phenylcarbazoles, oxidation was found to be reversible and the potential was affected by the types of substituents present. For 3,6-unprotected carbazoles, on the other hand, the oxidized forms can undergo dimerization.

The electrochemistry of carbazole compounds with other conjugated systems (aromatic compounds) is more complex and depends on either electronic effects or steric hindrance. If, as a result of steric hindrance, two aromatics are not well conjugated, the electrochemistry of the overall molecule can resemble that for the two parent compounds. For 3,6-disubstituted compounds, coupling can occur with an external aromatic via oxidation. This situation was reported by Sotzing et al. for 3,6-bisheterocycle- $N$-substituted carbazoles [35]. The authors performed oxidative polymerization, which proceeds through the alpha-positions of the external heterocyclic rings, since the 3-, 6-, and 9-positions of the carbazole are blocked. Moreover, in this case, the external rings exhibit high electron density, and oxidation occurs at quite low potentials - even lower than the potential for the oxidation of carbazole [35].
Fig. 8 Types of coupling that can occur after the oxidation of 3,6disubstituted carbazoles [11]<smiles>[R]c1ccc2[nH]c3ccc([R])cc3c2c1</smiles>

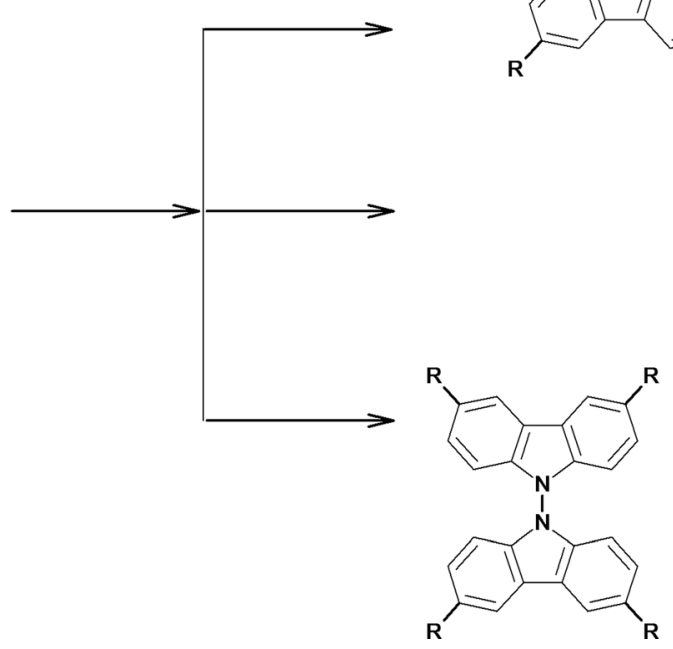<smiles>[R]c1ccc2[nH]c3c(-c4cc([R])cc5c4[nH]c4ccc([R])cc45)cc([R])cc3c2c1</smiles><smiles>[R]c1ccc2[nH]c3c(-n4c5ccc([R])cc5c5cc([R])ccc54)cc([R])cc3c2c1</smiles> 
In the case of carbazole copolymers with other aromatics, the corresponding rings are usually not coplanar, and the carbazole group is most often oxidized at a potential similar to that for the parent carbazole, giving a stable radical cation [23-26]. This has been reported for various aryl-ethynylene-carbazole copolymers or $N$-octylcarbazole-thiophene, $N$-octylcarbazolebithiophene, and $N$-octylcarbazole-benzothiadiazole. All of these copolymers undergo multistep oxidation. Oxidation of the carbazole fragment usually occurs at approximately $1.15 \mathrm{~V}$ vs $\mathrm{Ag} / \mathrm{AgCl}$, irrespective of the type of aryl group present [23].

Amino derivatives show different properties. As an example, we recall our previous work on isomeric 2,7- and 3,6linked carbazole trimers [27]. Both of the monomers described in that work (TC36 and TC27) undergo two-step oxidation (see Fig. 9). The presence of additional electron-donating nitrogen atoms in the molecule results in a substantial reduction in the initial oxidation potential compared to carbazole, but the polymer only forms during subsequent stages of oxidation. This can be explained by the fact, during the first steps, the middle region of the compound is oxidized, leading to the formation of a stable radical cation or dication; only further oxidation leads to reactive radicals in the outer carbazole groups.

The compounds TC 36 and TC27 show very different tendencies to polymerize. After the oxidation of TC27, a new strong polymer signal appears on the $\mathrm{CV}$ at approximately $0.84 \mathrm{~V}$, while the polymer signal at $0.9 \mathrm{~V}$ is very weak following the oxidation of the 3,6-substituted isomer, which means that a very small amount of the polymer is deposited on the electrode. To obtain similar amounts of both polymers, the oxidation of TC36 must be repeated many (hundreds of) times. The limited polymerization observed for TC36 is the result of a high tendency to form a

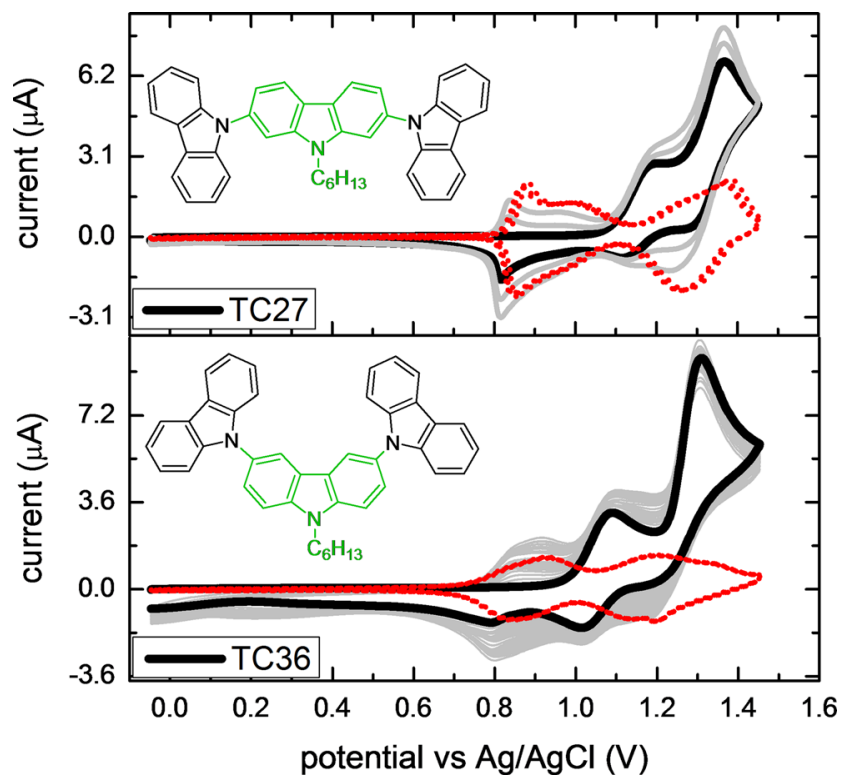

Fig. $9 \mathrm{CV}$ s for the oxidation of isomeric tricarbazoles (TC36 and TC27). In each case, the black line represents the first cycle, while the gray lines depict subsequent scans. The dotted red line shows the CV for the polymer in monomer-free solution

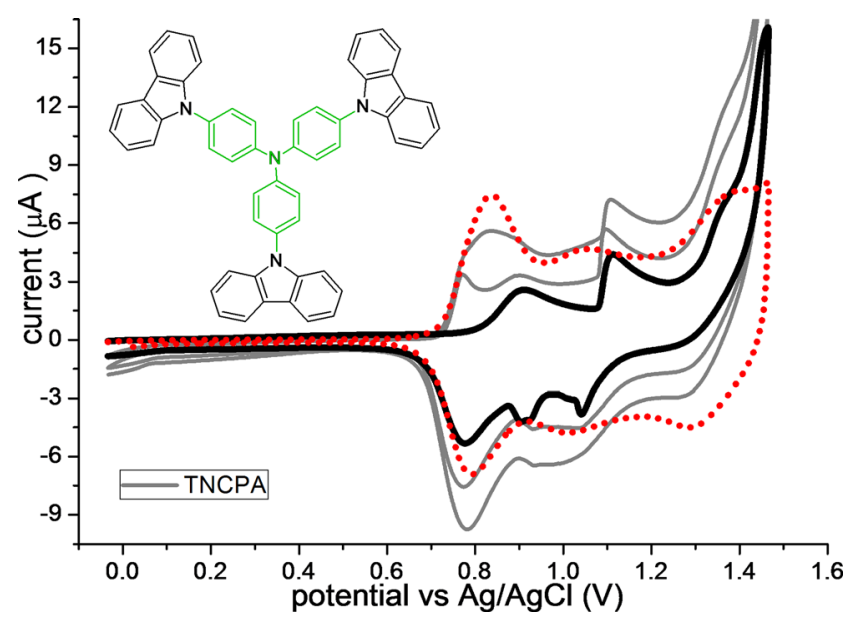

Fig. $10 \mathrm{CV}$ s for the oxidation of TNCPA and its polymer. The black line represents the first cycle while the gray lines depict subsequent scans. The dotted red line shows the CV for the polymer in monomer-free solution

stable phenylenediamine dication, as in the previously discussed case of 3-dimethylamino carbazole [2].

Similar stabilization is observed for other nitrogen-rich carbazoles [30].

In the case of the molecule TNCPA $\left(4,4^{\prime}, 4^{\prime \prime}\right.$-tris $(9$ carbazolyl)triphenylamine), the first and second stages of oxidation involve the formation of a stable phenylenediaminelike dication, and coupling occurs only during the third step of oxidation, at a potential a little higher than that seen for carbazole (Fig. 10). The latter example proves that, to some extent, stabilization can also occur for $N$-substituted carbazoles.

\section{Conclusions}

The examples cited above show that the electrochemistry of carbazole and its derivatives is quite complex, and the final reaction products and possible subsequent reactions may differ depending on the starting molecule. In general, the crucial factors appear to be the types of species formed during oxidation and their stabilities. Oxidation of carbazole derivatives is almost always initially associated with the formation of a radical cation, the stability of which dictates further reactions and products.

Carbazoles most commonly couple at the 3- or 6-position following oxidation, as these positions have the highest electron densities. All carbazoles with an unblocked 3- and/or 6position would then be expected to form at least a dimer after oxidation if there is no other steric hindrance. If substituents are present at these positions on the carbazole, they may either influence the electron density distribution of the molecule or physically block access to the active site, resulting in the formation of various products.

If the carbazole's 3-position is substituted, three situations are possible: no follow-up reaction because the most reactive sites are blocked; radicals are well dispersed in conjugated 
systems and are thus stabilized; or some intramolecular rearrangement occurs to form a dication. More complex cases involving the oxidation of conjugated systems and any subsequent reactions should be considered on a case-by-case basis.

Acknowledgments This work was financially supported by a grant from the Polish National Science Centre, project no. 2012/05/B/ST5/ 00745. We acknowledge the important contribution made to this work by Dr. Krzysztof Koziel.

Open Access This article is distributed under the terms of the Creative Commons Attribution 4.0 International License (http:// creativecommons.org/licenses/by/4.0/), which permits unrestricted use, distribution, and reproduction in any medium, provided you give appropriate credit to the original author(s) and the source, provide a link to the Creative Commons license, and indicate if changes were made.

\section{References}

1. Ambrose JF, Nelson RF (1968) Anodic oxidation pathways of carbazoles (I. Carbazole and $N$-substituted derivatives). J Electrochem Soc 115:1159-1163

2. Ambrose JF, Carpenter LL, Nelson RF (1975) Electrochemical and spectroscopic properties of cation radicals (III. Reaction pathways of carbazolium radical ions). J Electrochem Soc 122:876-893

3. Branch GEK, Smith JF (1920) A bivalent nitrogen derivative of carbazole. J Am Chem Soc 42:2405-2413

4. Branch GEK, Hall WW (1924) Oxidation of carbazole by silver oxide. J Am Chem Soc 46:438-445

5. Perkin WH, Tucker SH (1921) The oxidation of carbazole. J Chem Soc Trans 119:216-225

6. Maitland P, Tucker SH (1927) The dicarbazyls. Part III. The oxidation of carbazole and $\mathrm{N}$-alkylcarbazoles in acid solution. J Chem Soc C 1388-1392

7. Robinson B (1966) Tricarbazyl. Nature 210:520-521

8. Waters WA, White JE (1968) Reaction of the $N$-carbazolyl radical. J Chem Soc C 740-745

9. Morin HJF, Leclerc M, Adès D, Siove A (2005) Polycarbazoles: 25 years of progress. Macromol Rapid Commun 26:761-778

10. Yapi Abe S, Bernede JC, Delvalle MA, Tregouet Y, Ragot F, Diaz FR, Lefrant S (2002) Electroluminescent polycarbazole thin films obtained by electrochemical polymerization. Synth Met 126:1-6

11. Diamant Y, Chen J, Han H, Kamenev B, Tsybeskov L, Grebel H (2005) Electrochemical polymerization, optical and electrical characterizations of polycarbazole on single wall carbon nanotubes. Synth Met 151:202-207

12. Zhuang D-X, Chen P-Y (2009) Electrochemical formation of polycarbazole films in air- and water-stable room-temperature ionic liquids. J Electroanal Chem 626:197-200

13. Macit H, Sen S, Saçak M (2005) Electrochemical synthesis and characterization of polycarbazole. J Appl Polym Sci 96:894-898

14. Miao H-M, Zhang H-L, Xu J-K, Fan C-L, Dong B, Zeng L-Q, Zhao $\mathrm{F}$ (2008) Electrochemical polymerization of carbazole in acetic acid containing boron trifluoride diethyl etherate. Chin J Chem 26: 1922-1928

15. Huang Y, Lu B, Xu J, Zhu G, Chen S, Yue R (2012) Novel redoxactive polycarbazole-functionalized polycatechol network films produced by controlled electropolymerization. J Appl Polym Sci 126:1613-1622

16. Fulghum T, Abdul Karim SM, Baba A, Taranekar P, Nakai T, Masuda T, Advincula RC (2006) Poly(phenylacetylene) films cross-linked with electropolymerized polycarbazole precursors. Macromolecules 39:1467-1473

17. Reza B, Moghaddam RB, Pickup PG (2014) An electrochemical impedance study of thin polycarbazole films. Electrochim Acta 130:577-582

18. Ates M, Uludag N (2011) Capacitive behaviors and monomer concentration effects of poly(9-benzyl-9H-carbazole) on carbon fiber microelectrode. Fibers Polym 12:296-302

19. Ravindranath R, Ajikumar PK, Bahulayan S, Hanafiah NB, Baba A, Advincula RC, Knoll W, Valiyaveettil S (2007) Ultrathin conjugated polymer network films of carbazole functionalized poly(p-phenylenes) via electropolymerization. J Phys Chem B 111:6336-6343

20. Reyna-Gonzalez JM, Aguilar-Martınez M, Bautista-Martınez JA, Rivera E, Gonzalez I, Roquero P (2006) Influence of the acidity level on the electropolymerization of $N$-vinylcarbazole: electrochemical study and characterization of poly(3,6-N-vinylcarbazole). Polymer 47:6664-6672

21. Lapkowski M, Zak J, Karon K, Marciniec B, Prukała W (2011) The mixed carbon-nitrogen conjugation in the carbazole based polymer; the electrochemical, UVVis, EPR, and IR studies on 1,4-bis $[(E) 2-$ (9H-carbazol-9-yl)vinyl]benzene. Electrochim Acta 56:4105-4111

22. Wei Z, Xu J, Nie G, Du Y, Pu S (2006) Low-potential electrochemical polymerization of carbazole and its alkyl derivatives. $\mathrm{J}$ Electroanal Chem 589:112-119

23. Zhang X-C, Wang C-Y, Lai G-Q, Zhang L, Shen Y-J (2011) Conjugated opto/electroactive ethynylene-carbazole polymers with TTF as pendant group. Polym Bull 66:893-903

24. Liu Y, Wang C, Li M, Lai G, Shen Y (2008) Synthesis and spectroscopic and electrochemical properties of TTF-derivatized polycarbazole. Macromolecules 41:2045-2048

25. Witker D, Reynolds JR (2005) Soluble variable color carbazolecontaining electrochromic polymers. Macromolecules 38:7636-7644

26. Souharce B, Kudla CJ, Forster M, Steiger J, Anselmann R, Thiem H, Scherf U (2009) Amorphous carbazole-based (co)polymers for OFET application. Macromol Rapid Commun 30:1258-1262

27. Karon K, Lapkowski M, Grazulevicius JV (2014) Electrochemical and UV-vis/ESR spectroelectrochemical properties of polymers obtained from isomeric 2,7- and 3,6-linked carbazole trimers; influence of the linking topology on polymers properties. Electrochim Acta 123:176-182

28. Taranekar P, Fulghum T, Baba A, Patton D, Advincula R (2007) Quantitative electrochemical and electrochromic behavior of terthiophene and carbazole containing conjugated polymer network film precursors: EC-QCM and EC-SPR. Langmuir 23:908-917

29. Ssu-Kai C, Yi-Chun C, Guey-Sheng L, Yuhlong Oliver S (2012) Electrochemical and spectral characterizations of 9phenylcarbazoles. J Chin Chem Soc (Weinheim) 59:331-337

30. Karon K, Lapkowski M, Dabuliene A, Tomkeviciene A, Kostiv N, Grazulevicius JV (2015) Spectroelectrochemical characterization of conducting polymers from star-shaped carbazole-triphenylamine compounds. Electrochim Acta 154:119-127

31. Carlier R, Raoult E, Tallec A, Andre V, Gauduchon P, Lancelot JC (1997) Electrochemical behavior of mutagenic nitro and amino derivatives of carbazole. Electroanalysis 9:79-84

32. Reyna-González JM, Roquero P, Rivera E (2009) A comparative investigation between poly ( $N$-vinylcarbazole) and poly $(3,6-N$ vinylcarbazole): spectroscopy, conductivity, thermal and optical properties. Des Monomers Polym 12:233-245

33. Wei Z, Wang Q, Xu J, Du Y, Xia H (2008) Facile electrosyntheses of high tensile strength alkyl-bridged dicarbazole polymer films and its fluorescence spectra. J Polym Sci A Polym Chem 46:5232-5241

34. Seze E (2014) Synthesis and characterization of ethycarbazole and thiazole containing polymers. Electrochim Acta 122:141-149

35. Sotzing GA, Reddinger JL, Katritzky AR, Soloducho J, Musgrave R, Reynolds JR (1997) Multiply colored electrochromic carbazolebased polymers. Chem Mater 9:1578-1587 